\title{
Oral English Development in Virtual Class among Chinese Learners through Three Ways of Talking
}

\author{
Yang He \\ School of Education \\ Faculty of Social Sciences and Humanities \\ Universiti Teknologi Malaysia, Johor, Malaysia \\ Corresponding Author: hyang2009@qq.com \\ Abdul Rahim Salam \\ Language Academy \\ Faculty of Social Sciences and Humanities \\ Universiti Teknologi Malaysia, Johor, Malaysia
}

Received: 11/1/2021

Accepted: 12/10/2021

Published:1/24/2022

\begin{abstract}
Chinese learners are poor at oral English owing to a lack of practice. There is a high demand for opportunities to practice oral English effectively. This study investigates the use of three educationally significant ways of talking to Chinese learners' meaningful oral English development in one-to-one Computer- and Internet-Based Virtual Classes (CIBVC). It is a qualitative case study including two sets of data that contain 64 video-recorded lessons. One set of data are 32 class recordings from one participant as the primary data and the other are from another four participants as the supplementary data. Thematic analysis is employed to carry out this study and computer-assisted qualitative data analysis software is utilized to assist. The findings of this study discover effective ways of using the three ways of talking to conduct oral English teaching and learning practice. The results contribute to research into relating authentic communication in CIBVC to the discovery of effective oral English practice. Obtained practical implications are valuable references as predictors of successful teaching and learning outcomes. Keywords: Chinese learners, cumulative talk, disputational talk, exploratory talk, oral English, virtual class
\end{abstract}

Cite as: He, Y., \& Salam, A. (2022). Oral English Development in Virtual Class among Chinese Learners through Three Ways of Talking. Arab World English Journal (AWEJ) $2^{\text {nd }}$ Special Issue on Covid 19 Challenges (2) 120-134.

DOI: https://dx.doi.org/10.24093/awej/covid2.8 


\section{Introduction}

Today, humans live in a global community, and English has become the lingua franca commonly used worldwide. The extensive use of English makes English teaching and learning considerable in almost every country, and China is one of the countries. There are two major historic transitions regarding the development of English education in China. The first transition is that English displaced Russian as the dominant foreign language in 1961 after China had started to establish economic ties with western countries when Sino-Soviet relations had tensed in the late 1950s (Lam, 2002). The second transition is that the Chinese government adopted reform and open-door policies in 1978. Driven by the open-door policy, China aims to grow its economy and accelerate the progress of social revolution through building up cooperation with foreign countries in many aspects such as diplomacy, education, trade, etc. All these movements can progress only with the prerequisite of mutual communication. After the implementation of the open-door policy, China has increased investment in its public English teaching system from elementary to higher education (Zhao, 2012). To date, English learning has been growing unprecedentedly rapidly in the country.

Corresponding with the three Concentric Circles of Asian Englishes, China is classified as an Expanding Circle country, in which English is primarily used as a foreign language (Kachru, 2005). It is China or India that has the largest number of English learners (Wei \& Su, 2012), but the majority of Chinese EFL (English as a Foreign Language) learners are incompetent when it comes to oral communication. Only 3.53 percent of Chinese EFL learners reported that they were capable of conversing with others in English quite fluently (Wei \& Su, 2012). Although there is a vast amount of Chinese EFL learners, the number of fluent English speakers is minimal. Although Chinese learners are aware of the significance of English learning, they do not achieve a satisfying oral English proficiency level.

It mainly focuses on Chinese learners' lack of oral English practice. A notable part that is absent in Chinese education is oral English for the real world. It stands to reason that putting what has been acquired into practice is the most effective way to improve oral English. However, there is no good language environment in China. The only time when Chinese learners are exposed to an English speaking environment is in the classroom. They rarely need to speak English outside the classroom. Thus, they do not have sufficient opportunities to practice oral English. This phenomenon is named dumb English, which is well known to Chinese people, referring to the problem that students learn English but do not speak English. Referring to this phenomenon, teachers and students have realized that having an adequate overall understanding of English does not necessarily interpret to being a fluent English speaker. Besides, it is also one of the reasons why some Chinese EFL learners are good at receptive skills but are bad at productive skills. Therefore, it is not hard to understand why many Chinese EFL learners excel in areas such as linguistics and literature. Yet, their oral English ability is far from satisfactory. It is an overwhelming problem for English education in China, and it has not been addressed appropriately.

Innovative ways have been illuminated in English education by incorporating the advancement of Internet technology with the language learning process (Celik, 2013). For instance, fully online learning and blended or hybrid learning have been adopted to supplement traditional learning in brick and mortar schools. Fully online learning is conducted entirely 
through the internet; blended learning combines face-to-face and online teaching and learning (Kintu, Zhu, \& Kagambe, 2017). In other words, technology increases the diversity of language learning environments.

Nowadays, the availability of computers and the internet have provided language learners with a more individualized and interactive learning environment. For this research, the context is akin to one-to-one Technology-Enhanced Learning (TEL) proposed by Chan et al. (2006). In Chan et al.'s study, it mentions that "one-to-one" notion was coined by Elliot, Soloway, and Cathie Norris, which means a student has at least one device available, and the term TEL means digital technology for learning. In this research, the notion of one-to-one has a relatively broader but definite meaning. It not only refers to a ratio of one device (a computer, a tablet, a smartphone) per learner but also refers to a ratio of one device (a computer) per tutor. This is due to the other specific meaning of one-to-one regarding class participants, that is, there are two subjects having class together, and they are one tutor and one student. When using a device, a computer is recommended as it has a bigger screen, better hardware, and application software configuration. This is especially important for the tutor, because many of the feature such as a keyboard and a mouse can make a class run smoother. Getting back to TEL, CIBVC is investigated specifically for this research. CIBVC is the fifth and also the most recent generation of distance education (Moore \& Kearsley, 2012).

Having one-to-one CIBVC in this study means the tutor and the learner can see each other via webcam and have real-time communication in a fully online learning environment. Figure one below shows the interface of the investigated one-to-one CIBVC in this research.

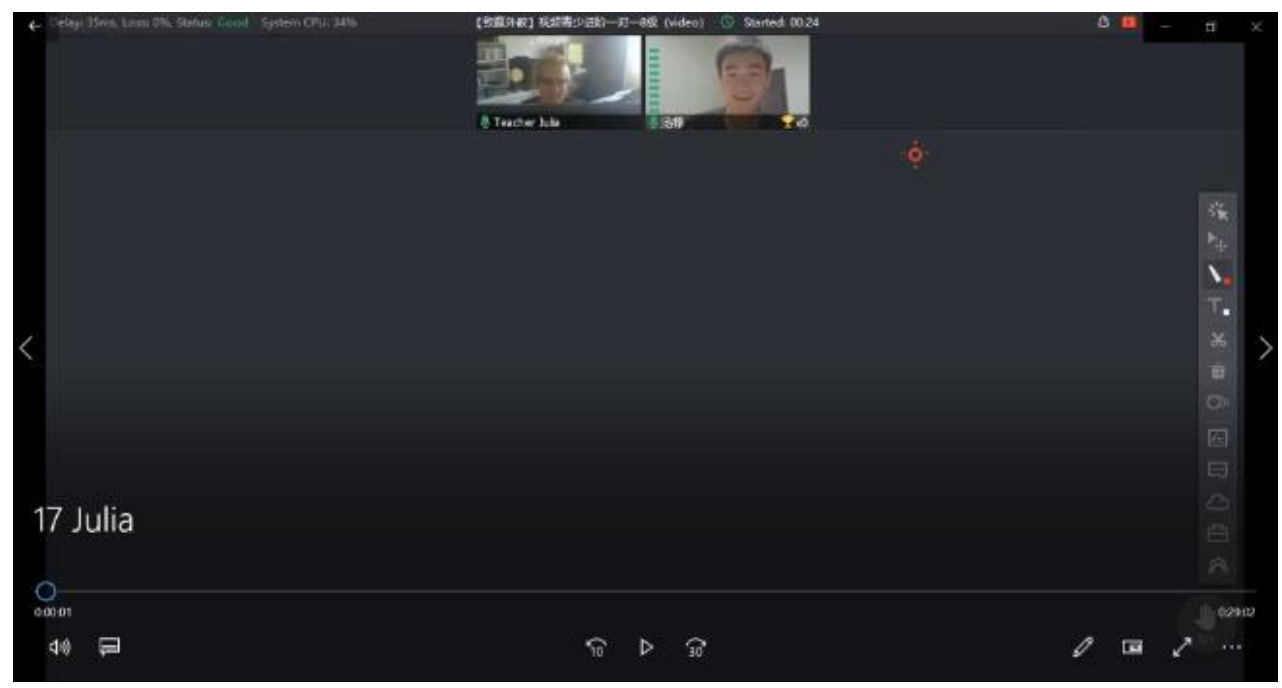

Figure 1. One-to-one CIBVC interface

This study investigates the conduct of an oral English course in this context by a leading provider of private educational services. It aims to explore Chinese learners' oral English development from the aspect of three educationally significant ways of talking, which are disputational talk, cumulative talk, and exploratory talk. The three ways of talking were characterized by Mercer, Wegerif, and Dawes (Fernández, Wegerif, Mercer, \& RojasDrummond, 2015) and can be distinguished based on the orientation of the talk. "Yes it is-no it 
isn't exchanges, commands and parallel assertions" (Mercer, 2000, p. 97) are the archetypal form of disputational talk. A salient characteristic of disputational talk is that interlocutors are not willing to adopt one another's viewpoints, and they assert their standpoint from a defensive position without a willingness to budge. Disputational talk shows a sharp contrast with cumulative talk which speakers are mutually supportive without negotiation (Mercer, 2000). As for exploratory talk, speakers constructively engage in discussion. "Knowledge is made publicly accountable and reasoning is visible in the talk" (Mercer, 2000, p. 98). Speakers express their thoughts with reasons and strive to reach an agreement with joint progress.

It was mentioned earlier that, by and large, Chinese EFL learners fail to reach fluency in oral English, which is mainly caused by a lack of practice and a poor language environment. With the maturity of computer and internet technology, an increasing number of English education institutions have been developing various platforms for Chinese learners to do oral English practice in an authentic online learning setting. However, research publications are scanty in this specific field. The researcher who conducted this study had experience on both sides of the screen, both as a tutor and a learner. From the researcher's first-hand experience both teaching and learning, this research topic is highly worth investigating. Specifically, the investigation of this study concerns in what ways the three ways of talking effectively facilitate Chinese learners' oral English development in one-to-one CIBVC. It aims to benefit Chinese learners from discovering acceptable and practical oral English practice. This study intends to answer the following research question:

In what ways do the three educationally significant ways of talking contribute to meaningful development of Chinese learners' oral English practice in one-to-one CIBVC?

\section{Literature Review}

Intermental Development Zone (IDZ) is the core theoretical underpinning of this study, which matches the particular context investigated in this research. IDZ is a new concept proposed by Mercer (2000), drawing on scaffolding and Zone of Proximal Development (ZPD) for understanding how interpersonal communication aids learning and conceptual development (Fernández et al., 2015). The seminal notion of scaffolding was introduced by Wood, Bruner, and Ross (1976), which was initially used to describe a tutorial process in which an expert assists someone who is less experienced to carry out a task and achieve a goal that they are unable to finish alone. To a large extent, a body of literature concurrently discusses scaffolding together with ZPD. ZPD was developed by Lev Semenovich Vygotsky in the late 1920s (Shabani, Khatib, \& Ebadi, 2010). Vygotsky (1978) defined ZPD as "the distance between the actual development level as determined by independent problem solving and the level of potential development as determined through problem solving under adult guidance or in collaboration with more capable peers" (p. 86). Scaffolding is related to ZPD in a way that a more capable individual supports the learning of a less capable individual so that the weaker person can successfully perform a task within the domain of their ZPD. In regard to this research, the tutor supports the learner's oral English practice while they speak with each other discussing different topics in one-to-one CIBVC.

IDZ "is meant to capture the way in which the interactive process of teaching-and-learning rests on the maintenance of a dynamic contextual framework of shared knowledge, created 
through language and joint action" (Fernández et al., 2015, p. 56). In this particular research, the dynamic contextual framework refers to the mutual communicative interactions between the tutor and learner for helping the learner practice their oral English through the conversations built on their collaborative discussions.

IDZ is "a dialogical phenomenon, created and maintained between people in interaction" (Fernández et al., 2015, p. 57). To make a comparison between the ZPD and the IDZ, Mercer (2000) stated that the IDZ puts more emphasis on getting to know "the quality of teaching-andlearning as an intermental or interthinking process" (p. 141) rather than assessing individuals that the ZPD does. Mercer further explained that the focus of IDZ is still on how a learner makes progress when being given guidance during an activity, which falls in line with the original idea of the ZPD proposed by Vygotsky. However, it is more distinctly related to variable contributions that both teacher and learner jointly make.

According to Fernández et al. (2015), the linked concepts of scaffolding and the ZPD are applied to asymmetrical teaching and learning contexts, while IDZ can be applied to both asymmetrical and symmetrical contexts. The distinction between the two contexts is that learners cooperate with peers of similar levels of ZPDs in symmetrical scaffolding (Tabrizi, Behnam, \& Saeidi, 2019). This study draws attention to asymmetrical teaching and learning context in which the learner communicates with the tutor who is more competent in oral English. Mercer, Wegerif, and Dawes characterized three educationally significant ways of talking, and they are disputational talk, cumulative talk, and exploratory talk (Fernández et al., 2015). According to Fernández et al., the typology of the three emanated from analyses of children talking in groups to deal with various curriculum tasks. Solidarity is the feature of cumulative talk which strives for agreement without proposing critiques or reasons; every participant wants to win in the disputational talk, which is more individualized and competitive without attempts to achieve a joint understanding or to reason together; pursuing the best solutions together with collective endeavor is the orientation of exploratory talk, aiming to "critical, cooperative, situated reasoning" (Fernández et al., 2015, p. 59).

Mercer (2004) proposed the dynamic and contextualized nature of talk as collective thinking and claimed that a historical aspect and a dynamic aspect are the two aspects involved in any specific interaction that two people engage in solving a problem together. A historical aspect refers to the interaction occurring in the context of a particular institution and cultural background. What is said by speakers may invoke knowledge from their joint past experience. A dynamic aspect refers to speakers' shared understanding of their common knowledge that is constantly developing.

The pioneering research of this field has investigated dialogues featuring the three ways of talking. For example, Mercer $(2004,2008)$ explored how the three types of talking work during group-based activities to make all the group members collaboratively tackle problems and complete assigned tasks. Fernández et al. (2015) investigated symmetrical scaffolding between a group of children who were given the Raven's Standard Progressive Matrices test. This test is used to measure abstract reasoning. It revealed that IDZ was present in the pre- and postintervention tests based on how they communicated. The intervention was a program where they were explicitly taught how to talk together effectively. The children combined their intellectual 
resources and solved the problems in the post-intervention tests. On the one hand, relevant studies are limited to group-based activities among children (Fernández et al., 2015; Hartikainen, 2008; Mercer, 2004, 2008). On the other hand, they focus on problem-solving such as finding a solution to the prevention of eutrophication of lakes through the talk. In other words, their central focus is language as a tool to think together. Their research is limited to group-based activities among children and also leaves a research gap in examining the effective use of the three ways of talking to facilitate oral language learning itself.

The researcher of this study follows the concepts of IDZ and the three types of talking proposed in the study by Fernández et al. (2015). Nonetheless, this research does not directly replicate Fernández et al.'s study. Fernández et al.'s study is conducted in a symmetrical teaching and learning context, while this research focuses on an asymmetrical context. Besides, Fernández et al. promoted using the three types of talking as social ways of thinking and investigated dialogues between participants in groups. However, this research casts attention on using the three to construct conversations as the collaborative work made by two subjects who are the tutor and the learner. In addition, Fernández et al.'s study investigated that participants used the three to manage to solve problems. For this research, its emphasis is on how the three facilitates communication between the tutor and the learner to practice oral English.

Recent findings of the ZPD study indicated that people seem to learn more from others due to seeing different perspectives rather than simply because their partner is more capable (Shokouhi \& Shakouri, 2015). This implication is meaningful and is also the leading cause of the new concept IDZ. This concept is helpful to know how interpersonal communication aids learning and conceptual development (Shokouhi \& Shakouri, 2015). "The IDZ is a dynamic frame of reference which is reconstituted constantly as the dialogue continues, so enabling the teacher and learner to think together through the activity in which they are involved" (Mercer, 2002, p. 6). When conducting a study relevant to IDZ and the three types of talking, it is essential to review the research by Neil Mercer. Mercer is a professor from the faculty of education at the University of Cambridge in the UK, who is the pioneer that coined the concept of IDZ and has significantly contributed to the research field of IDZ and the three types of talking. By and large, there are limited studies relevant to IDZ and three educationally significant ways of talking. More research-based studies are imperatively needed.

This study investigates the effective use of the three educationally significant ways of talking to Chinese learners' oral English development in virtual classes. Chinese EFL learners are bad at oral English. The IELTS (International English Language Testing System) official website (https://www.ielts.org/teaching-and-research/test-taker-performance) issued the academic speaking test mean band scores by test takers from the top 40 first language backgrounds in 2018; it revealed that test takers whose first language is Chinese get the lowest score of 5.46. Referring to the statistics recorded by Shen (2009) from the official IELTS website (www.ielts.org), the mean band score of the IELTS academic speaking test was 5.26, achieved by test takers from China. It is frustrating that the mean band score merely went up by 0.2 in ten years. Statistics for Chinese EFL learners' oral English ability are scarce because there is no mandatory national exam. Oral English tests are not included in most English exams that they need to take at all different education levels. 
Lalima and Dangwal (2017) stated that the educational system is undergoing a transition stage currently. They claimed that the educational system is working on embracing new technology and exploring new paths to achieve the aim of providing quality educational chances for all. The integration of technology has received positive feedback to assist learning. For instance, a digital interactive audio capturing tool benefited English teacher trainees that addresed problems with media richness or a lack of natural conversational elements in a Computer-Supported Collaborative Learning environment (Salam, Mustaffa, Abdullah, \& Salam, 2015); virtual communities in an online English language learning forum could serve as a scaffold for learners where they motivated one another or as a place for learners who needed an environment to practice English with others of similar interest (Deris, Koon, \& Salam, 2015); hybrid e-learning promoted motivation and collaborative work among college students (Yauri, Salam, \& Kahar, 2016); online English instruction increased shy students' willingness to speak in front of a screen (Al-Samiri, 2021).

The researcher agrees with Schweighofer, Weitlaner, Ebner, and Rothe (2019) that it is indisputable that TEL has been becoming widespread. However, previous studies primarily focused on similar TEL types such as virtual education, distant learning, etc. in higher education (Al-Nofaie, 2020; Bozavl1, 2021; Celik, 2013; Deris, Koon, \& Salam, 2015; Kintu, Zhu, \& Kagambe, 2017; Schweighofer et al., 2019; Yauri, Salam, \& Kahar, 2016). Higher education has the educational purpose of improving students' overall academic achievements while a private education company has the business purpose of improving learners' particular skills. Besides, private education companies that provide virtual classes have been developing their exclusive online platforms for many years while many universities started to offer virtual classes on popular social media in the past two years because of the outbreak of Covid-19 pandemic. In part these companies are more experienced and professional in the development of individuals' particular skills through online teaching and learning. This study aims to bridge this research domain gap by investigating oral English practice in CIBVC provided by a private education company.

\section{Methods}

This research is a qualitative case study. A case study investigates and reports "the real-life, complex, dynamic and unfolding interactions of events, human relationships and other factors in a unique instance" (Cohen, Manion, \& Morrison, 2018, p. 376). This study uses qualitative methods in terms of the procedures for data collection. Patton (1985) explained that "qualitative research is an effort to understand situations in their uniqueness as part of a particular context and the interactions there" (as cited in Merriam, 2002, p. 5). In this study, the particular context is one-to-one CIBVC, and the interaction is communication between the tutor and the learner in class.

This research adopted thematic analysis and Computer-Assisted Qualitative Data Analysis Software (CAQDAS) is utilized to help with the analysis process. This research used CAQDAS because it helps organize data and files created for storing the data in a more organized and systematic way, makes it easier for the researcher to manage and access the recorded data, and facilitates the whole process of data transcription (Cohen, Manion, \& Morrison, 2018). Specifically, NVivo 12 Plus was used when transcribing the conversation between the tutor and the learner in the one-to-one CIBVC. Thematic analysis deals with "identifying, analyzing and 
reporting patterns (themes) within data" (Braun \& Clarke, 2006, p.79). The researcher decides to use thematic analysis so that copious amounts of data can be reduced for a concise subjectrelated interpretation to address the research question. Dialogues between the tutor and the learner are extracted and categorized as disputational talk, cumulative talk, or exploratory talk through thematic analysis. The conversations are classified according to the features of the three ways of talking. The researcher of this study read the whole book Words \& Minds: How we use language to think together (Mercer, 2000) and then summarized a detailed description of the three types of talking in regards to their features and descriptors or content as shown in Table one below. Features are themes coded in data analysis.

Table 1. Interpretation of the three educationally significant ways of talking

\begin{tabular}{|c|c|c|}
\hline Types & Features & Descriptors/Content \\
\hline Disputational talk & $\begin{array}{l}\text { Unwilling to take on the other person's point of } \\
\text { view } \\
\text { Consistent reassertion of one's own opinions } \\
\text { Defensive, uncooperative } \\
\text { Strive for control } \\
\text { Cycles of assertion and counter-assertion with } \\
\text { short utterances that rarely include explicit } \\
\text { reasoning } \\
\text { Competitive } \\
\text { Individualized decision-making }\end{array}$ & $\begin{array}{l}\checkmark \quad \text { Yes, it is-no, it isn't } \\
\text { exchanges, commands, } \\
\text { and parallel assertions }\end{array}$ \\
\hline Cumulative talk & $\begin{array}{ll}\text { - } & \text { Build on each other's contributions } \\
\text { - } & \text { Mutually supportive } \\
\text { - } & \text { Dncritical acceptance of what partners say } \\
\text { - Non-competitive } \\
\text { Individual differences of perception or judgment } \\
\text { are minimized. }\end{array}$ & $\begin{array}{ll}\checkmark & \text { Instant, uncritical yes }\end{array}$ \\
\hline Exploratory talk & $\begin{array}{l}\text { Engage critically but constructively } \\
\text { Relevant information is offered for joint } \\
\text { consideration. } \\
\text { Proposals are challenged and counter-challenged } \\
\text { with reasons, and alternatives are offered. } \\
\text { Critical and explicit evaluations } \\
\text { Reach joint conclusions } \\
\text { Knowledge is made publicly accountable, and } \\
\text { reasoning is visible in the talk. } \\
\text { Explicit criticisms, reasons, and explanations } \\
\text { Constant negotiation } \\
\text { Discover and strive for new and better ways of } \\
\text { jointly making sense in a committed but } \\
\text { unselfish manner rather than being concerned } \\
\text { with protecting individual or joint identities and } \\
\text { interests. } \\
\text { Co-reasoning }\end{array}$ & $\begin{array}{ll}\checkmark & \text { Because } \\
\checkmark & \text { If } \\
\checkmark & \text { Why } \\
\checkmark & \text { I think }\end{array}$ \\
\hline
\end{tabular}

\section{Participants}

Non-probability sampling was used, and specifically, convenience sampling to choose the participants included in this research. Convenience sampling means that "members of the target population are selected for the study if they meet certain practical criteria, such as geographical proximity, availability at a certain time, easy accessibility, or the willingness to volunteer" (Dörnyei, 2007, pp. 98-99). There is no equal chance of participation in the investigation for 
each unit of a population in non-probability sampling (Alvi, 2016). The researcher can only approach part of the learners who take the particular class. Tuition fees of this course is costly and sharing video-recorded classes is a private thing. Therefore, it is only feasible for the researcher to invite learners who they had developed a good rapport with.

The participants of this research are Chinese EFL learners who have one-to-one CIBVC to practice their oral English. A total of 5 learners took part in this study. They registered for an oral English practice program named Winning English. This program is open to teenagers and adult Chinese EFL learners. Koolearn, a professional online education company founded in 2005, provides this service. It is a subordinate company of New Oriental Education and Technology Group, and it was established in 1993. The group is a leading provider of private education in China. Among the five participants, one signed up for lessons for teenagers, and the other four registered for adult lessons.

\section{Research Instruments}

Video-recorded class is the instrument used in this study. Video recordings may be ideal for classroom research because the need for real-time coding can be substituted in this way (Dörnyei, 2007). In this research, the class is automatically video-recorded during the one-to-one CIBVC. It works through the automatic class recording function of the application on which the tutor and the learner have class together. Participants shared their video-recorded classes with the researcher through a link generated to review the class. The researcher used IDM (Internet Download Manager) to download the recordings and then carefully and confidentially saved them as the research data. By doing so, it can avoid having expired links after the end of the learners' course duration. In total, 64 video-recorded classes were collected from the participants and were divided into two sets. One set of data is 32 recordings from one of the participants as the primary data. The other set of data is the other 32 recordings, eight recordings from each of the other four participants as supplementary data. One class duration is around 28 minutes on average. The participants had classes with 29 tutors. Twenty-three of the tutors are native English tutors (NETs), and six of them are Chinese English Tutors (CETs). To keep their personal information confidential, this study uses the participants' and the CETs' English names and the NETs' first and last letters of their first name.

\section{Research Procedures}

The procedures for conducting this study include three main stages. The first stage is the preliminary preparation stage. The researcher taught the investigated course as a part-time tutor for around one and a half years. Aside from that, the researcher signed up for a 30 lesson course, completing it over a period of five months. The teaching and learning experience helped the researcher get familiar with the course by obtaining insight from a tutor's and a learner's perspectives, and have the opportunity to approach the participants. The second stage is data collection. Data collection took around ten months as each participant registered for the course on different dates, and had classes at their convenience to finish all of their lessons. The third stage is data analysis. It took the researcher nine months to manually transcribe all of the collected class recordings, complete data analysis, and present the findings in an organized way. 
Arab World English Journal (AWEJ) 2nd Special Issue on Covid 19 Challenges January 2022

Oral English Development in Virtual Class among Chinese Learners

He \& Salam

\section{Results}

It reveals that the effective use of three ways of talking is dynamic and flexible in actual conversations in class. Dialogues categorized as disputational talk, cumulative talk, or exploratory talk demonstrate intertwined features of the three. Disputational talk extracts show features of cumulative talk and exploratory talk; cumulative talk and exploratory extracts mutually embody certain features of each other. However, there are fundamental distinctions. For disputational talk, refutation always occurs, and the conclusion of dialogue follows either the tutor or the learner's statements. For cumulative talk, the tutor and the learner always agree with each other, and the conclusion of dialogue follows either the tutor or the learner's opinions. For exploratory talk, the tutor and the learner constantly challenge each other to reach a joint conclusion.

A total of 10672 speaking turns were transcribed, and 1301 of the speaking turns from 47 out of 64 class recordings are relevant to the investigation of this study. Among them, disputational talk extracts take up 168 speaking turns from 14 class recordings. Although the identified extracts of the three ways of talking do not only show one single feature of their type, there is always one salient feature that stands out and thus they can be classified into that particular theme. As for the disputational talk extracts, they fall into five themes. These five themes are competitive, consistent reassertion of one's own opinions, individualized decision-making, striving for control, and being unwilling to take on the other person's point of view.

It is not hard to understand why disputational talk extracts show features of cumulative talk and exploratory talk, taking the purpose of this particular one-to-one CIBVC into consideration. Whatever the topic is, the tutor and the learner focus on practicing oral English rather than making either correct or wrong solution to a problem. To take a closer look at the effective dialogues, it discovers more elaborative features. In class, it is always the tutor who refutes the learner's statements while the learner never tries to reject the tutor's statements. However, contrary opinions are not fully rejected except for when the tutor directly rejects an inappropriate reply from the learner that hinders a class activity from being conducted smoothly. Besides, the tutor rebuts the learner's opinions with explicit reasoning while trying to maintain a positive atmosphere. In addition, there are times when refutation is for giving encouragement and compliment but not arguing, such as the learner underestimates their oral English ability.

Identified effective disputational talk extracts contribute to the learner's meaningful oral English development in many aspects. The tutor helps to correct their speaking errors (e.g., grammatical mistakes and incorrect pronunciation), know more about English-speaking countries' lifestyle and avoid speaking of a relevant misconception in future speeches, use typical words of a subject to stay on topic, and show a good command of the related vocabulary words, make the learner know the reasons behind their speech defects and give suggestions according to noticed defects, provide a description specifically, introduce background knowledge related to the discussed subject as additional assistance with oral output, increase vocabulary (e.g., avoid ambiguity in words, differentiate words of similar meanings, broaden understanding of English words with multiple meanings in different contexts, use phrasal verbs).

There are 843 speaking turns from 39 class recordings identified as effective cumulative talk extracts. They are classified into four themes: build on each other's contributions, individual 
differences of perception are minimized, mutually supportive, and uncritical acceptance of what partners say. Findings reveal that the tutor gives encouraging and positive feedback; the class atmosphere is lively, relaxing and supportive; speaking errors are not pointed out directly in general; the tutor and the learner are mutually supportive (e.g., give instant yes to each other's statements, not only accept each other's opinions but also supplement the opinions with complementary examples to enrich the talk); the way they communicate with each other can be compared to writing an English composition with topic sentences and supporting details; no disagreement occurs during the conversation; the tutor strongly approves of the learner's replies and then puts forward better answers; the tutor appears cheerful and sound enthusiastic about conversing with the learner; the tutor treats the learner as their equals and cares about the learner's opinions in a polite manner, and the learner looks happy and is pretty active in talking with the tutor; the tutor and the learner share the same attitudes towards things (e.g., take on each other's ideas because of a personal habit in common); the tutor tries to let the learner speak up as much as possible; the dynamic interaction between the tutor and the learner indicates how scaffolding operates in practice; the tutor and the learner exchange different perspectives on the same subject; there is empathy between the tutor and the learner; the tutor tries to engage with the learner (e.g., speak in an easily understandable way, request a further clarification when a communication breakdown occurs); the tutor has background knowledge about subjects under discussion; subjects under discussion are closely connected with the topic of a lesson.

These cumulative talk extracts are beneficial for the learner to improve their oral English. On the one hand, the tutor teaches in many different ways: the tutor fine-tunes and revises the learner's sentences to be more precise and make them sound more natural (e.g., use more accurate alternative wording, summarize points proposed by the learner with local terms in a more advanced sentence); The tutor utilizes a four-step process of assisting the learner in practicing oral English (firstly, the learner poses a question; secondly, the tutor gives a clarification; thirdly, the learner expresses their understanding based on the provided clarification; fourthly, the tutor justifies the correctness of the learner's understanding); the tutor helps to increase the learner's vocabulary (e.g., improve on the variety of the learner's words); the tutor articulates a word appropriately to solve the learner's confusion about the correct pronunciation of the word; the tutor corrects the learner's speaking errors with explanations and common mistakes are incorrect tense, missing an article, incorrect use of nouns' singular or plural form, etc.; the tutor gives the learner a hint to extend the subject discussed further; the tutor knows things about the subject and this helps the communication flow as they could lead the discussion to go further and provide information when the learner has a difficulty expressing themselves; the tutor gives the learner suggestions to help them with their oral English practice (e.g., use digital technology to assist learning process such as e-book and e-dictionary, think harder to answer questions, have classes with different tutors so as to get used to different tones and talking styles, etc.); CETs and a few NETs who can speak a bit of Mandarin can communicate with the learner in Chinese when a breakdown occurs, even help to interpret the learner's thoughts in English.

On the other hand, the learner learns from the effective cumulative talk extracts in many ways: the learner imitates the way the tutor speaks (e.g., incorporate expressions in their speeches, pick up the sentence structure, etc.); the learner borrows ideas from the tutor as useful input and manages to use the ideas in their own words as output; the learner learns to express the 
same thing with different expressions in a flexible way; the learner can develop their oral English by conversing with the tutor on a subject through exchanging opinions (e.g., persuasive points surface during discussion and make statements logical and convincing); empathy helps to precisely express what the learner wants to say but fails to make themselves clear because of limited oral English proficiency.

Two hundred and ninety-two speaking turns from 11 class recordings are effective exploratory talk extracts. Six themes surface from the speaking turns, and they are challenged and counter-challenged proposals with reasons and alternatives, committed but unselfish manner rather than being concerned with protecting individual identities and interests, constant negotiation, critical and explicit evaluations, offering relevant information for joint consideration, and publicly accountable knowledge and visible reasoning. The extracts show that interruptions occur during the argument; the tutor and the learner argue in mild disapproval; the tutor and the learner agree with each other on some of the points rather than totally deny each other's statements; specific examples are shared to clarify each other's viewpoints; some of the tutor's opinions are variants of the learner's; they show a good attitude for exploring the subject (e.g., willing to know each other's contrasting points of view instead of asserting oneself); they do not give up or compromise their opinions, instead, they keep discussing until reach a joint conclusion; the learner identifies with the tutor owing to similar personal experience; CETs do not sound as natural as NETs and CETs' sentences are not as accurate as their counterparts', however, CETs take advantage of sharing the common knowledge with the learner and thus the communication between CETs and the learner is effective.

The effective exploratory talk extracts contribute to the learner's meaningful oral English development in many ways: the learner can open their mind and come up with more viewpoints from different perspectives on a topic; the tutor helps the learner to increase vocabulary; practical suggestions are given in line with the learner's oral English performance in class (e.g., watch English cartoons with subtitles to help with pronunciation); speaking errors are corrected to improve accuracy; the learner would take the initiative to pose questions to explore a subject that they show little interest at first as the dialogue goes along; the tutor and the learner discover a better way that satisfies both of them to work out a more suitable expressions in discussion; There is no communication breakdown; exchange acceptable ideas helps to further discussion expanded upon a subject; language input assists output production (e.g., the learner imitates the way the tutor expresses a point to introduce another similar point of this type); the conversation is more informative and meaningful.

\section{Discussion}

The findings demonstrate that disputational talk show features of cumulative talk and exploratory talk, and the later two types of talk mutually embody each other's certain features. Owing to their intertwined features, the three educationally significant ways of talking contribute to the meaningful development of Chinese learners' oral English practice in CIBVC in many aspects as the research results demonstrated. All identified effective talks fall into the coded themes summarized from the features of the three types of talk by Mercer (2000).

It is obvious to see from the findings that cumulative talk constitutes the largest part of the identified effective dialogue extracts that contribute to the learner's meaningful oral English development, followed by exploratory talk and disputational talk. This is not very consistent with 
what Mercer (2008) found in his research. Mercer (2008) ascertained that disputational talk and cumulative talk are more common than exploratory talk during group work. However, the researcher of this study believes that the findings are reasonable. First of all, it is clear that both the tutor and the learner are consciously aware of building up a good atmosphere. Under the circumstances, disputational talk is unlikely to occur much in class. Besides, the tutor and the learner discuss various topics to practice oral English rather than work out a solution to an issue. They have different perspectives on things, which helps to complement each other's statements and further expand upon the discussion.

Mercer promotes exploratory talk, and the researcher of this study supports that. Results show that all three ways of talking can be effective to help the learner with their oral English development in certain circumstances. Exploratory talk appears the most acceptable among the three as it is clear that the tutor and the learner have a deeper constructive discussion on a subject. It maintains a good balance in its presentation of different opinions. Hartikainen (2008) also ascertained that exploratory talk is the most effective way to collaborate in her research on pupil talk in an inquiry-oriented instruction.

On a micro-level, the findings of this study provide valuable insight about the predictors of success for Chinese learners to improve their oral English in one-to-one CIBVC. It gives online oral English teaching and learning service providers more critical and reflective thinking so that they can further optimize the appropriateness, effectiveness, and quality of their programs. This can be very helpful to enhance the teaching and learning experience significantly and offers excellent potential for achieving better teaching and learning outcomes. On a macro-level, the research of this nature adds profound academic knowledge to the literature review. These research results can be a meaningful reference to support the sustainable development of this teaching and learning mode.

\section{Conclusion}

This study aims to shed light on in what ways the three educationally significant ways of talking contribute to the meaningful development of Chinese learners' oral English practice in one-to-one CIBVC. The findings of this study provide identified effective dialogue extracts to demonstrate how the three types of talk facilitate oral English practice elaboratively. The research topic of this study is highly relevant to the current environment. The outbreak of COVID-19 has boosted online education both nationally and internationally. Studies relevant to this research field are trending academic issues. Indexed quality journals and conferences call for related papers. Future studies are needed to better establish the theoretical base and guarantee that such an innovative mode of education has a systematic foundation for enduring development in oral English teaching and learning.

\section{About the authors:}

Yang He is a full-time $\mathrm{PhD}$ candidate at School of Education, Faculty of Social Sciences and Humanities, Universiti Teknologi Malaysia. She is interested in the research field of English education, technology in language learning, oral English teaching and learning. ORCiD ID: https://orcid.org/0000-0001-6920-4843

Abdul Rahim Salam is an Associate Professor at Language Academy, Faculty of Social Sciences and Humanities, Universiti Teknologi Malaysia. His research interests are computer 
Arab World English Journal (AWEJ) 2nd Special Issue on Covid 19 Challenges January 2022

Oral English Development in Virtual Class among Chinese Learners

He \& Salam

integrated language lab/classroom, blended learning, flip classroom, computer mediated communication, technology supported face-to-face collaborative learning, and ESL teacher training. ORCiD ID: https://orcid.org/0000-0002-8023-1014

\section{References}

Al-Nofaie, H. (2020). Saudi University Students' Perceptions towards Virtual Education During Covid19 Pandemic: A Case Study of Language Learning via Blackboard. Arab World English Journal, 11(3), 4-20. DOI: https://dx.doi.org/10.24093/awej/vol11no3.1

Al-Samiri, R. A. (2021). English Language Teaching in Saudi Arabia in Response to the COVID-19 Pandemic: Challenges and Positive Outcomes. Arab World English Journal (AWEJ) Special Issue on Covid 19 Challenges (1), 147-159. DOI: https://dx.doi.org/10.24093/awej/covid.11

Alvi, M. (2016). A Manual for Selecting Sampling Techniques in Research. Munich Personal RePEc Archive.

Bozavl1, E. (2021). Is Foreign Language Teaching Possible Without School? Distance Learning Experiences of Foreign Language Students at Ataturk University During the Covid-19 Pandemic. Arab World English Journal, 12(1), 3-18. DOI: https://dx.doi.org/10.24093/awej/vol12no1.1

Braun, V., \& Clarke, V. (2006). Using thematic analysis in psychology. Qualitative research in psychology, 3(2), 77-101. Retrieved from https://www.tandfonline.com/toc/uqrp20/current

Celik, S. (2013). Internet-assisted technologies for English language teaching in Turkish universities. Computer Assisted Language Learning, 26(5), 468-483. DOI:10.1080/09588221.2012.692385

Chan, T. W. et al. (2006). One-to-one technology-enhanced learning: An opportunity for global research collaboration. Research and Practice in Technology Enhanced Learning, 1(1), 3-29. Retrieved from https://telrp.springeropen.com/

Cohen, L., Manion L., \& Morrison, K. (2018). Research Methods in Education (8th ed.). Routledge.

Deris, F. D., Koon, R. T. H., \& Salam, A. R. (2015). Virtual Communities in an Online English Language Learning Forum. International Education Studies, 8 (13): 79-87. DOI:10.5539/ies.v8n13p79

Dörnyei, Z. (2007). Research Methods in Applied Linguistics: Quantitative, Qualitative, and Mixed Methodologies. Oxford: Oxford University Press.

Fernández, M., Wegerif, R., Mercer, N., \& Rojas-Drummond, S. (2015). Re-conceptualizing "Scaffolding" and the Zone of Proximal Development in the Context of Symmetrical Collaborative Learning. Journal of Classroom Interaction,50(1), 54-72. Retrieved from https://jciuh.org/

Hartikainen, A. (2008). Making Meanings: Pupil Talk in Inquiry-Oriented Instruction. Nordic Studies in Science Education, 4(1), 256-268. Retrieved from https://journals.uio.no/nordina/

Kachru, B. B. (2005). Asian Englishes Beyond The Canon. Hong Kong: Hong Kong University Press.

Kintu, M. J., Zhu, C., \& Kagambe, E. (2017). Blended learning effectiveness: the relationship between student characteristics, design features and outcomes. International Journal of Educational Technology in Higher Education, 14(7), 1-20. DOI: 10.1186/s41239-017-0043-4

Lalima, D. \& Dangwal, K. L. (2017). Blended Learning: An Innovative Approach. Universal Journal of Educational Research, 5(1), 129-136. DOI: 10.13189/ujer.2017.050116

Lam, A. (2002). English in education in China: policy changes and learners' experiences. World English, 21(2), 245-256. DOI: 10.1111/1467-971x.00245

Mercer, N. (2000). Words \& Minds: How we use language to think together. London: Routledge.

Mercer, N. (2002). Developing Dialogues. In G. Wells., \& G. Claxton (Ed.), Learning for life in the C21st: Sociocultural perspectives on the future of education (pp. 1-22). Oxford: Blackwell.

Mercer, N. (2004). Sociocultural discourse analysis: analysing classroom talk as a social mode of thinking. Journal of Applied Linguistics, 1(2), 137-168. Retrieved from https://journals.equinoxpub.com/JAL/index

Mercer, N. (2008). The seeds of time: Why classroom dialogue needs a temporal analysis. Journal of the Learning Sciences, 17(1), 1-48. Retrieved from https://www.tandfonline.com/toc/hlns20/current 
Arab World English Journal (AWEJ) 2nd Special Issue on Covid 19 Challenges January 2022

Merriam, S. B. (2002). Qualitative research in practice: Examples for discussion and analysis. San Francisco, CA: JOSSEY-BASS.

Moore, M. G., \& Kearsley, G. (2012). Distance education: A Systems View of Online Learning (3rd ed.). USA: WADSWORTH CENGAGE Learning.

Salam, A. R., Mustaffa, F. Y., Abdullah, T., \& Salam M. S. (2015). The Concept Of Technology Supported Face-to-face Collaborative Learning Via Digital Interactive Audio Capturing Tool. Jurnal Teknologi, 75 (3), 1-6. Retrieved from https://journals.utm.my/jurnalteknologi/index

Schweighofer, P., Weitlaner, D., Ebner, M., \& Rothe, H. (2019). Influential factors for technologyenhanced learning: professionals' views. Journal of Research in Innovative Teaching \& Learning, 12(3), 268-294. DOI: 10.1108/JRIT-09-2017-0023

Shabani, K., Khatib, M., \& Ebadi, S. (2010). Vygotsky's Zone of Proximal Development: Instructional Implications and Teachers' Professional Development. English Language Teaching, 3(4), 237248. Retrieved from https://www.igi-global.com/journal/international-journal-computer-assistedlanguage/41023

Shen, X. (2009). A Ten-Day Step-by-step Guide to the IELTS Speaking Test. China MACHINE PRESS.

Shokouhi, M., \& Shakouri, N. (2015). Revisiting Vygotsky's Concept of Zone of Proximal Development: Towards a Stage of Proximity. International Journal of English Literature and Culture, 3(2), 6063. DOI: 10.14662/IJELC2015.006

Tabrizi, H. M., Behnam, B., \& Saeidi, M. (2019). The effect of soft vs. hard scaffolding on reading comprehension skill of EFL learners in different experimental conditions. Cogent Education, 6, 1-13. Retrieved from https://www.tandfonline.com/toc/oaed20/current

Vygotsky, L. S. (1978). Mind in Society: The Development of Higher Psychological Processes. The USA: Harvard university press.

Wei, R., \& Su, J. (2012). The statistics of English in China: An analysis of the best available data from government sources. English Today, 28(3), 10-14. DOI: 10.1017/S0266078412000235

Wood, D., Bruner, J. S., \& Ross, G. (1976). The Role Of Tutoring In Problem Solving*. Journal of Child $\begin{array}{llll}\text { Psychology and Pychiatry, 17, 89-100. Retrieved from } & \end{array}$ https://acamh.onlinelibrary.wiley.com/journal/14697610

Yauri, A. M., Salam, A. R., \& Kahar, R. (2016). Implementing Hybrid E-Learning on English as a Foreign Language in Islamic College. Arab World English Journal, Special Issue on CALL(3), 227-238. Retrieved from https://awej.org/

Zhao, Z. (2012). EFL Teaching and Reform in China's Tertiary Education. Journal of Language Teaching and Research, 3(6), 1098-1104. DOI:10.4304/jltr.3.6.1098-1104 